\title{
Regional Variations of Compensation Awards: The Quantum of Damages in Personal Injury and Wrongful Death Claims in Western Europe
}

\author{
by Paul Szöllösy*
}

This paper concerns the standard of compensation in personal and fatal injury cases in various countries of Western Europe. As is generally known, there are substantial differences in the legal bases of liability, according to the traditions, the evolution and the aspirations of the national legal systems in Europe. Even if these diverging legal bases affect the system and the level of compensation, I shall not deal with the bases of tort law, but rather focus on the variations in the amount of damages awarded for physical injury or wrongful death in Western-European countries.

Already in 1972, and again in 1981/82, I had the privilege of lecturing in the Scandinavian countries on this subject. ${ }^{1}$ I used then some topical cases, known to Swiss Re's Claims section, as a model to calculate the amounts likely to be awarded for serious personal injury or wrongful death in various countries. An updating of the sums assessed some 6-7 years ago may not only show the evolution that has occurred since but also indicate current development trends regarding the level of compensation.

When speaking about the standard of compensation, I try to answer the question: What is the total quantum of damages due by the person liable (the "tortfeasor") or his liability insurer to the victim or the latter's dependants and the subrogating social insurance carrier, according to the general rules and practice of the tort law, i.e. without reference to aviation accidents.

In this connection, one has to be aware of the influence of social security schemes on the compensation system in Europe. The claimant normally cannot collect double compensation in Continental Europe; in other words, the social insurance benefits he gets must be deducted from his claim for tort damages. In most European countries the social security systems have a right of subrogation against the person liable for the accident or against his liability insurer. In the case of comparisons with countries like Great Britain and the Scandinavian countries where the social security carriers have no right of subrogation, it must be borne in mind that this has a substantial influence on the level of tort compensation. In these countries the considerable social security benefits which the injured person receives, apart from tort damages, do not have to be reimbursed by the tortfeasor or his insurer (and therefore do not appear in the following examples).

\footnotetext{
* Paul Szöllösy, Dr. iur., is Claims Consultant for the Swiss Reinsurance Company in Zurich.
}

${ }^{1}$ See Scandinavian Ins. Q. 1983 pp. 128-141. 
In my 1982 lecture, I demonstrated the quantum of damages in the light of six "model cases", of which I would now like to present you three, with updated sums of awards.

Case No. 1. The most severe of the examples chosen : a 20-year-old Spanish girl of an upper middle class family and not yet employed suffered incomplete tetraplegia and consequent total disability following a road accident. After one and 1/2 years in hospital she now requires permanent care for about 12 hours daily.

Case No. 2. An accident at work in England causing serious bodily injury: a plant fitter, aged 34 at the time of the court decision and with a former annual net income of about $£ 6,000$, became paraplegic (paralysed from the waist down). He spent about six months in hospital and is $80 \%$ disabled. However, despite the remaining ability to work, he has so far not been able to pursue a gainful activity.

Case No. 3. At the age of 36 a nuclear plant worker died of an overdose of drugs, erroneously prescribed by his doctor in the treatment of his grave migraine condition. $\mathrm{He}$ was survived by his widow (36) and three children (14, 11 and 6). Doctor's and Chemist's liability was admitted four years after death.

How would these cases be assessed in those countries where we wish to compare the compensation practice? Tables 1-3 show, for cases 1, 2 and 3, the corresponding amounts, which I tried to calculate according to the standards and methods applied in the countries concerned.

As already mentioned, the basis used for comparison is the amount which the person liable or his liability insurer has to pay according to the law of torts. It includes both the direct claim of the injured person and the right of recourse of those social security institutions which, on the basis of legal or statutory subrogation, can reclaim their benefits paid to the victim from the person liable or his insurer.

When looking at my comparative tables, one should be aware that they by no means contain extremely high awards for the countries concerned. Whereas I obviously had to take model cases with the most serious injuries or the death of the breadwinner, I have chosen victims with rather modest actual earnings or earning prospects. The awards shown do, therefore, in no case exceed the average amount granted for similar injury or loss of support in the particular country.

I should also mention that e.g. in medical malpractice cases with injuries comparable to my model case No. 1 in Great Britain awards exceeding $£ 650,000$ have already been published. ${ }^{2}$ In France Ffr. 10-12 Million have also been awarded to victims with spinal or brain injuries, and in Switzerland compensation amounting to or exceeding 3 Million Sfr. may be granted to a fully disabled victim in an exceptional case.

To close and sum up my brief presentation, I would comment on the figures shown as follows :

- Whereas some 6-7 years ago there was a striking difference of $4: 1$ in the compensatin level of Western European countries like Germany, France or Switzerland on the one hand and Italy or Spain on the other, this discrepancy has now gradually been reduced to a proportion of about $2.5: 1$.

\footnotetext{
${ }^{2}$ Cf. World Ins. Rep. 5.8.1988, No. 343, p. 11.
} 


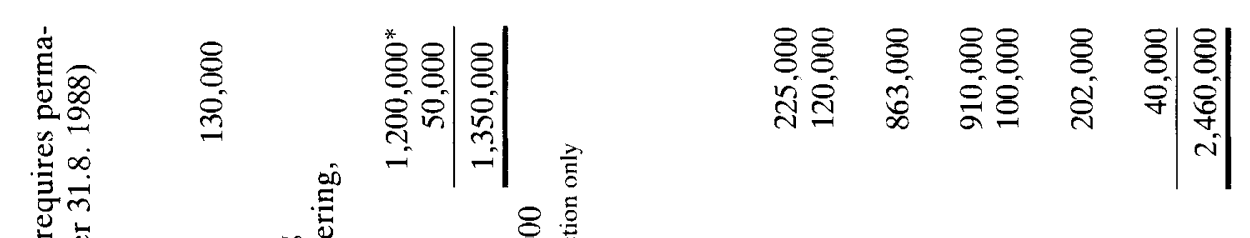

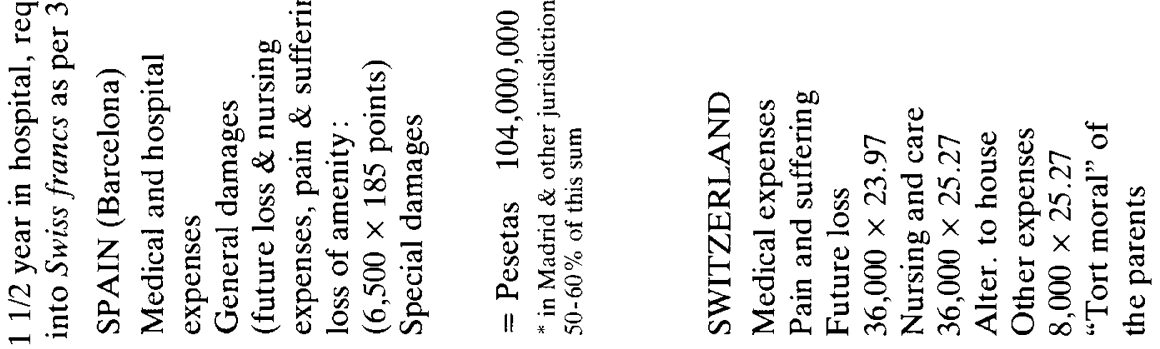

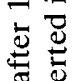

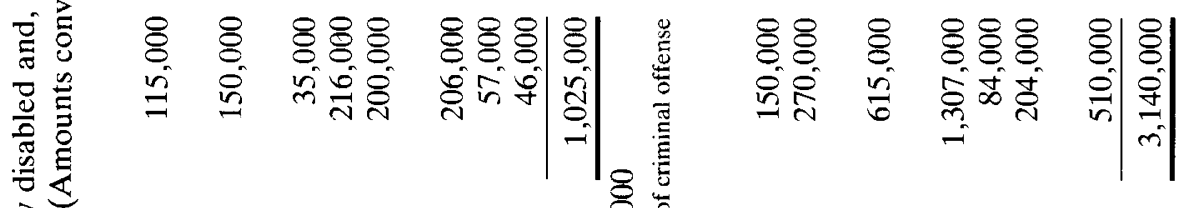

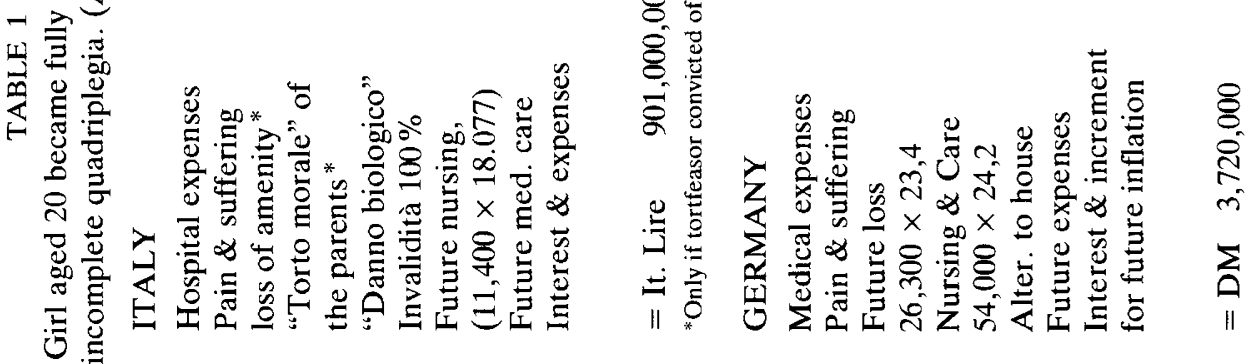

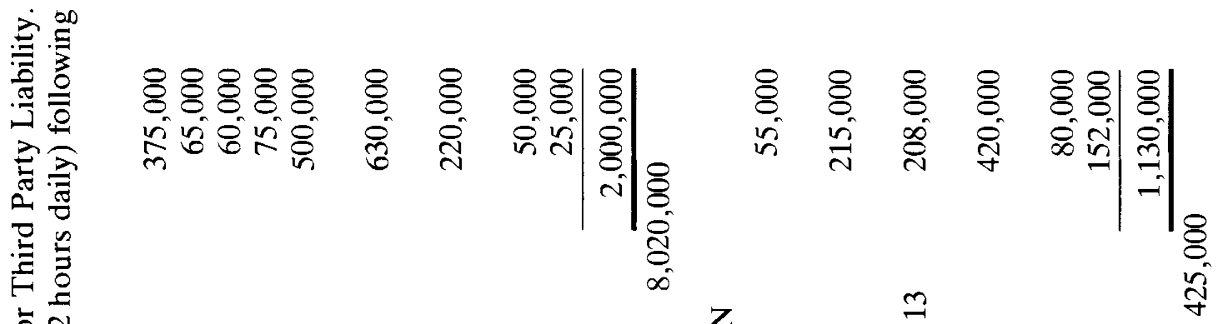

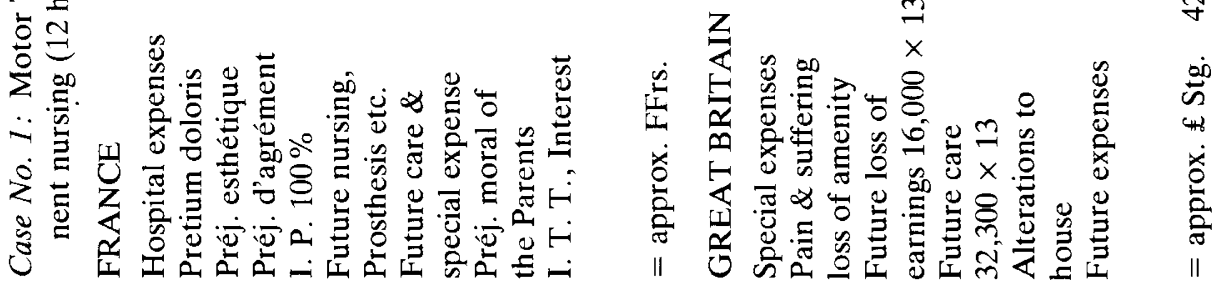




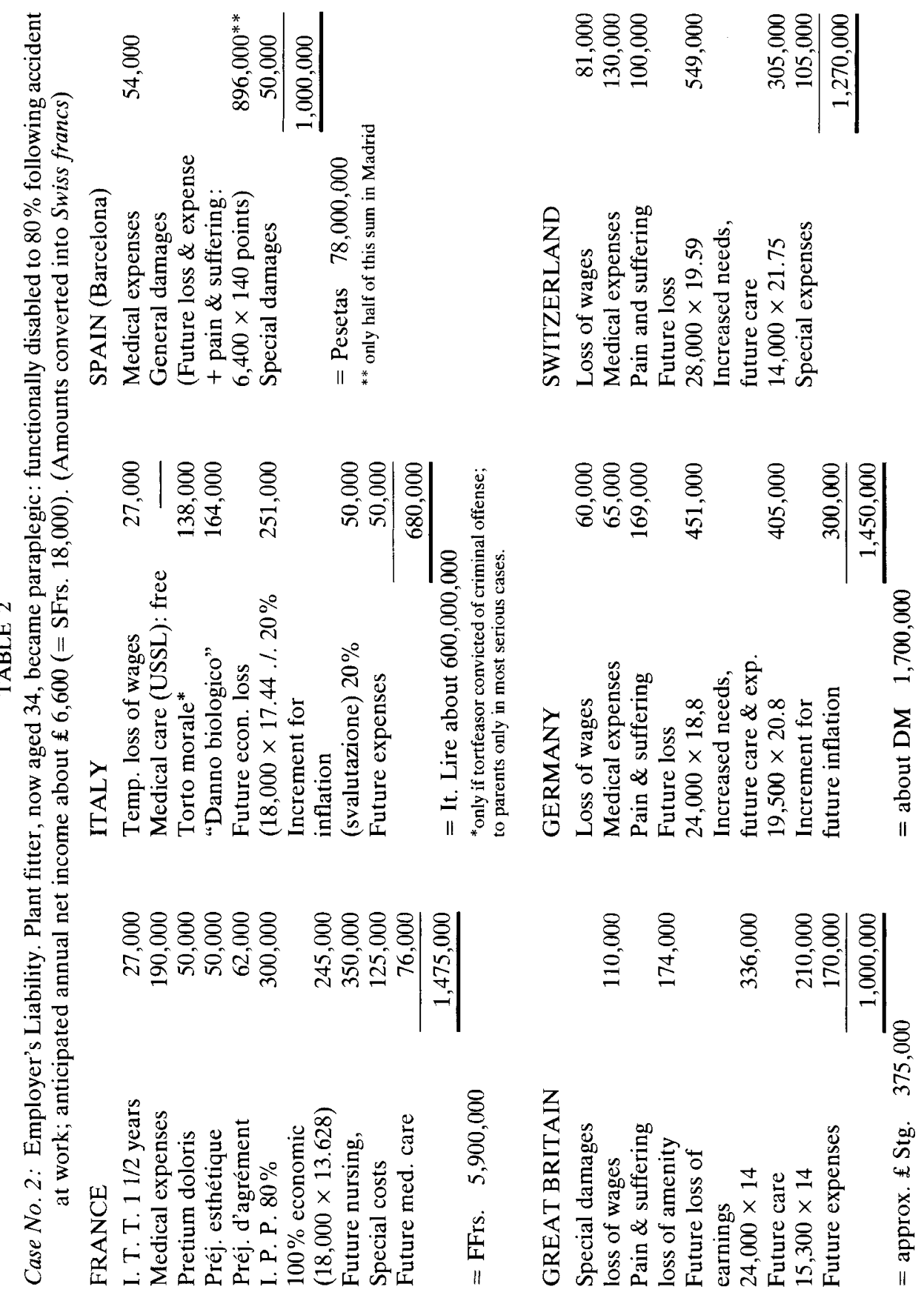




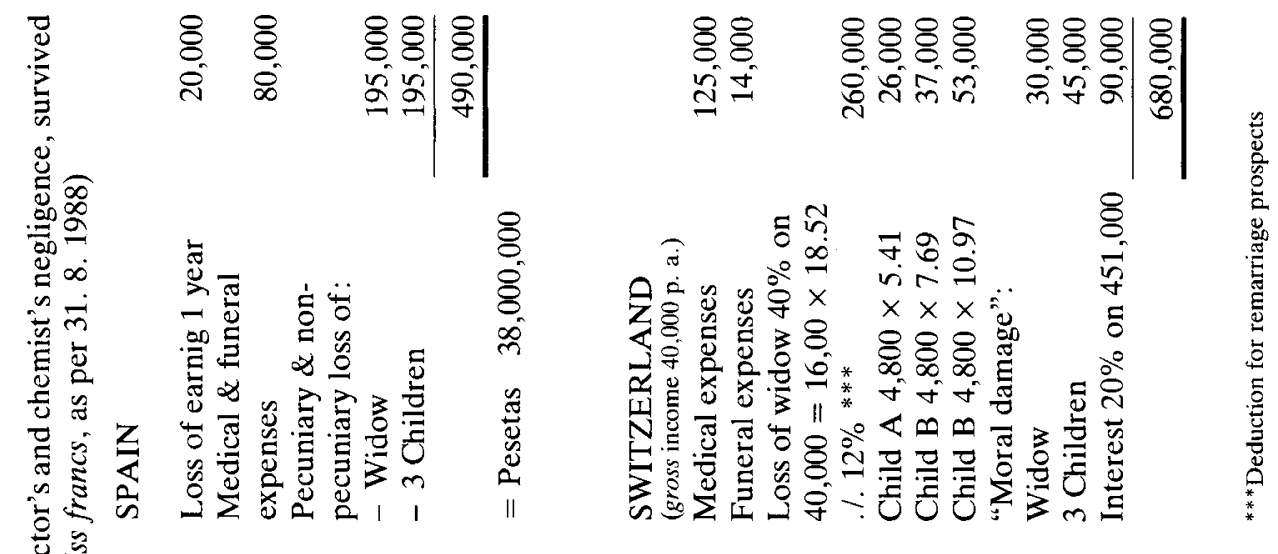
造产

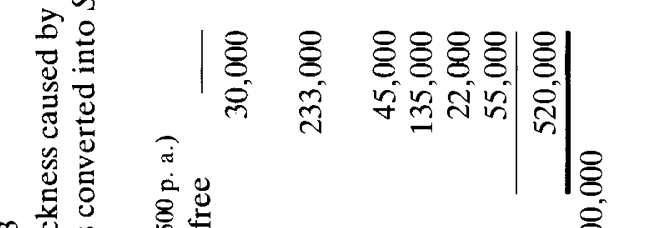

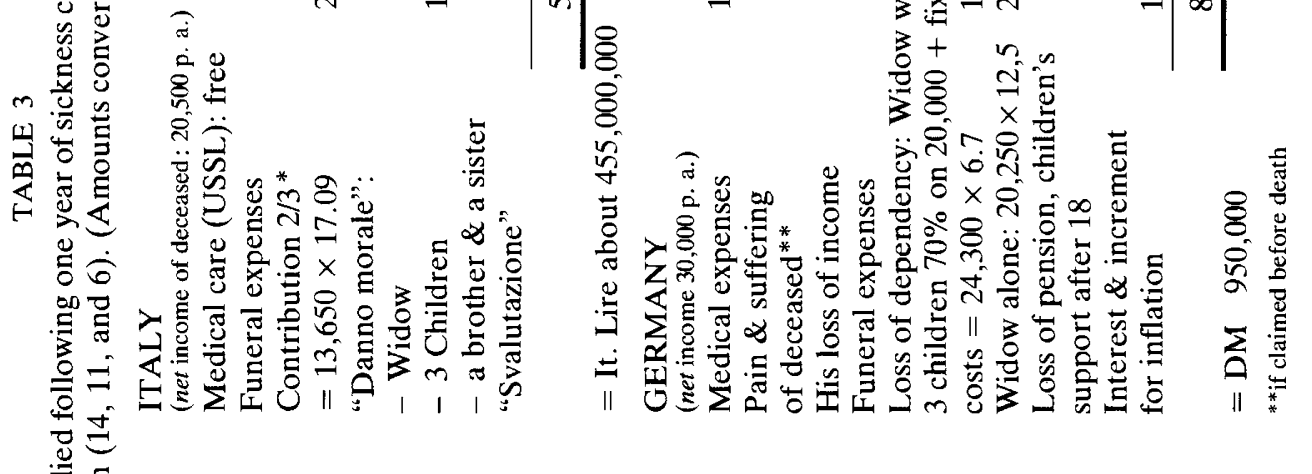

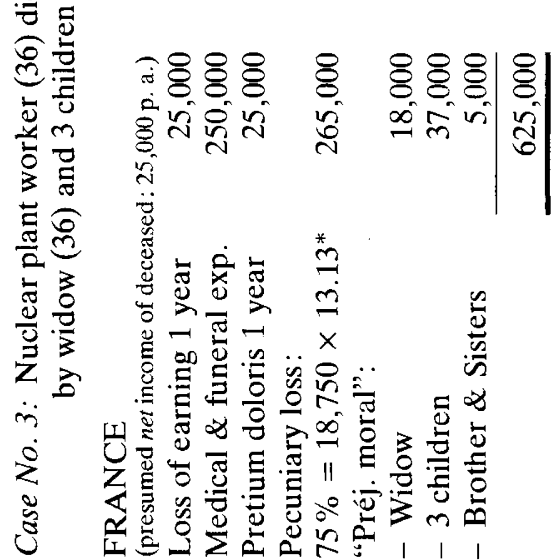

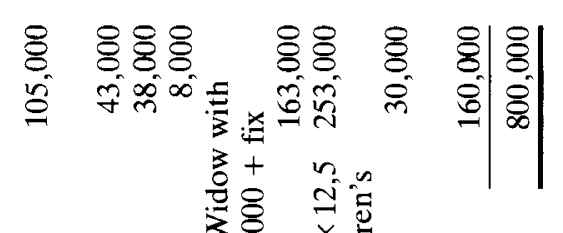

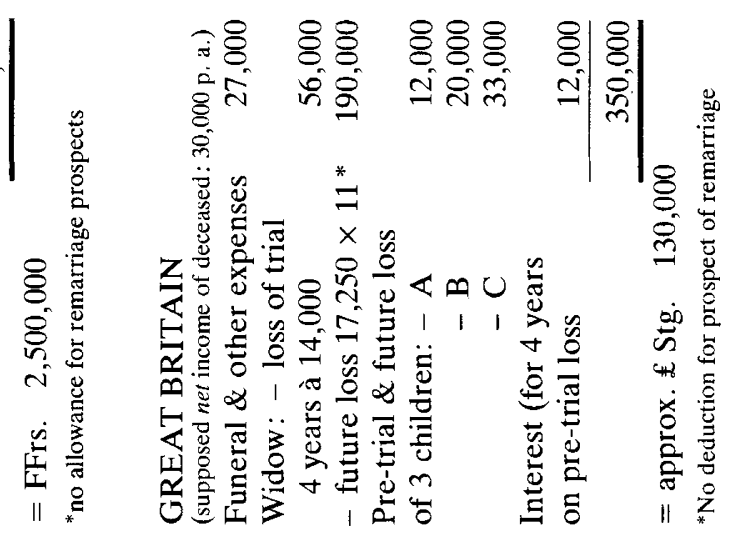




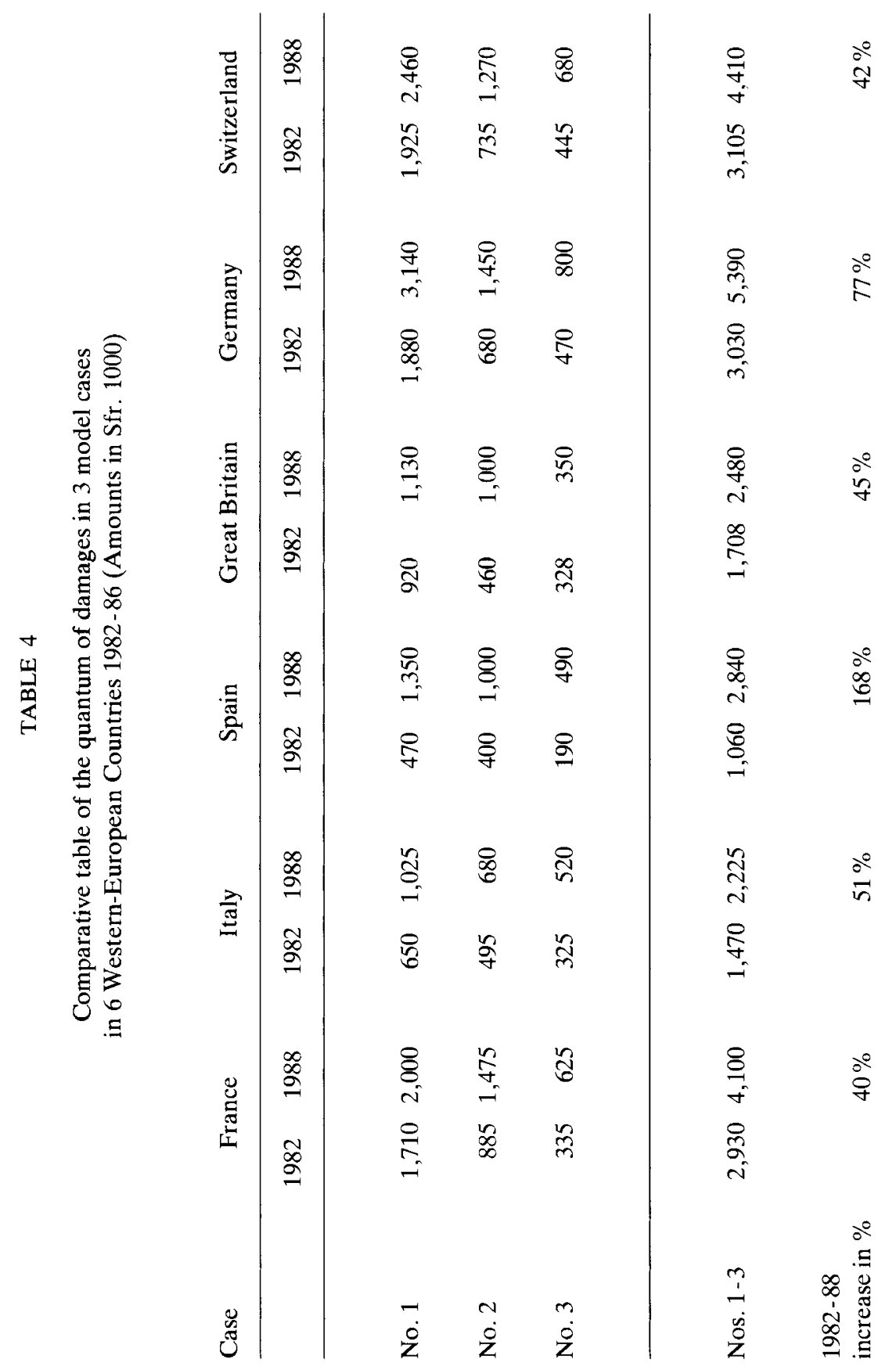


- The courts of the Southern European countries, especially those in the north of Spain, strive to adjust their awards for personal injury to the Western European standard, i. e. the level of damages increases here even more than in Western Europe in the long run.

- The quantum of damages granted for personal or fatal injury tends to rise, generally speaking, more than the inflation rate of prices or wages.

- In every Western European country, the compensation awarded for serious injury cases or loss of support exceeds very substantially the liability limits imposed by the Warsaw Agreement and the Hague Protocol on aviation accidents. 